7. Child Lang. 40 (2013), 945-970. (C) Cambridge University Press 2012.

The online version of this article is published within an Open Access environment subject to the conditions of the Creative Commons Attribution-NonCommercial-ShareAlike licence $<$ http://creativecommons.org/licenses/by-nc-sa/2.5/ $>$. The written permission of Cambridge University Press must be obtained for commercial re-use.

doi:I0.IOI 7/So3050009I 20004I 4

\title{
The French noun phrase in preschool children with SLI: morphosyntactic and error analyses*
}

\author{
PHAEDRA ROYLE \\ School of Speech Language Pathology and Audiology, University of Montreal \\ and Centre for Research on Brain, Language, and Music, Montreal
}

AND

ISABELLE STINE

School of Speech Language Pathology and Audiology, University of Montreal

(Received I 7 Fune $201 \mathrm{I}$ - Revised I 5 December $20 \mathrm{I}$ - Accepted I6 Fuly $20 \mathrm{I}_{2}-$

First published online I4 September 2012)

\section{ABSTRACT}

We studied spontaneous speech noun-phrase production in eight French-speaking children with SLI (aged 5; O to 5; I I) and controls matched on age $(4 ; \mathrm{I} O$ to $5 ; \mathrm{II}$ ) or MLU (aged $3 ; 2$ to $4 ; \mathrm{I}$ ). Results showed that children with SLI prefer simple DP structures to complex ones while producing more substitution and omission errors than controls. The three groups also showed distinct error patterns. Children with SLI appeared to have difficulty with phonological processes involved in liaison, elision, and contraction, whereas control children tended to make more lexical errors. These data support models of reduced morphosyntactic and syntactic abilities in this population, and suggest that morphophonological processes should also be integrated into descriptive models of SLI.

[*] This research was funded by an FQRSC Grant to P. Royle (2006-NP-Io4790, 2005-2008) and a COPSE summer scholarship to I. Stine (IRSC, 2008). We thank the families and children that volunteered, Margaret McKyes for her editing, and two anonymous reviewers and the action editor for their comments on previous versions of this article. The first author thanks Marie-Do and Meïr for hosting her in Vientiane during the writing of this article. Address for correspondence: Phaedra Royle, Université de Montréal, Faculté de médecine, École d'orthophonie et d'audiologie, C.P. 6r28, Succursale Centre-Ville, Montréal (Québec), $\mathrm{H}_{3} \mathrm{C}$ 3J7. tel: 5I4-343-6 I I I, o925; fax: 5 I4-343-2 I 5 ; e-mail : phaedra.royle@umontreal.ca 
INTRODUCTION

Specific language impairment (SLI) is a language learning disability that occurs without any obvious cause such as hearing impairment, mental retardation, autism, or other neurological or cognitive disorders (Leonard, I 998). In Quebec, it is usually identified when a child presents lower than normal expressive or receptive language abilities in the presence of preserved cognitive functions in other domains, with persistent linguistic difficulties over time (the diagnosis is dysphasie; OOAQ, 2004). The diagnostic criteria for SLI are stricter than those used in the USA (Elin Thordardottir \& Namazi, 2007). We translate the OOAQ (2004) definition of dysphasie as: "a primary linguistic deficit in the expressive or expressive-receptive spheres with variable deficits in more than one linguistic domain: phonology, morphology, syntax, semantics, or pragmatics [...] heterogeneity in manifestations across individuals, and within individuals, [...] persistence and variability over time, in addition to the probability that little development will be seen without intervention." The child must also be over four years of age, have been followed regularly over several meetings, and have been evaluated using differential diagnostics. Slow evolution and persistence of the delay or difficulties are part of the diagnosis. No time period is specified, but in clinical settings a minimum of six months is typical. Presently, there is no clear linguistic marker for the early identification of SLI in French.

SLI can be difficult to identify in pre-school-aged children for a number of reasons. In French and other languages, one problem is that late talkers, who will eventually resolve their developmental delay, are often hard to distinguish from children who truly have a persistent linguistic impairment (Bates \& Goodman, I997; Paul, I99 I ; Thal, Tobias \& Morrison, I99 ; see also Desmarais, 2007, Demarais, Sylvestre, Meyer, Bairati \& Rouleau, 2008, and Ellis \& Thal, 2008, for systematic literature reviews on late talkers, mainly learning English). In addition, studies of French language development in pre-school children (Elin Thordardottir \& Namazi, 2007; Le Normand, Leonard \& McGregor, I993; Royle \& Elin Thordardottir, 2008) reveal few differences between normal and impaired language development on spontaneous-speech measures that have previously been useful in distinguishing children with SLI from normally developing children in other languages, such as English, Spanish, or Swedish (Leonard, Salameh \& Hansson, 200 I Restrepro, I998; Rice \& Wexler, I996).

A study of global morphosyntactic development in the spontaneous speech production of French-speaking children aged 3;2 to 4;6 found almost no differences between children with language impairment and agematched controls (Elin Thordardottir \& Namazi, 2007). The impaired children's morphosyntactic productivity was similar to that of younger children matched on mean length of utterance in words (MLUw), and error rates were negligible (lower than $\mathbf{I} \%$ ) in all groups, indicating that error

$$
946
$$


pattern analysis is not useful for establishing language impairment or identifying atypical linguistic behaviour in these children. A previous study of French children aged 4; 0 to 6 ; 0 found similar strengths in determiner use (Le Normand et al., I 993). These data contrast with those from studies of children speaking other languages. Pre-school-aged English-speaking children with SLI aged 4;4 to 5;8 show marked difficulties inflecting verbs, omitting the past tense $-e d$ and third person present morpheme $-s$ in spontaneous speech (Rice \& Wexler, I996). Spanish-speaking American children aged 5;0 to 7; I show difficulties with determiners in the noun phrase, making gender substitutions (e.g. producing *la agua for el agua 'det.m/f water' 'the water'), or omitting them (Restrepro \& GutierrezClellen, 200I). Swedish-speaking children aged 4;3 to 5;7 show difficulties with genitive $-s$ and plural - er marking on nouns (all errors were omissions), determiner omissions, and gender substitutions with determiners and adjectives (neuter for uter gender or vice versa) in the noun phrase (Leonard et al., 200I). Finally, a subgroup of Italian-speaking children aged 4;2 to Io; 7 show high levels of determiner omission in obligatory contexts (Bottari, Cipriani, Chilosi \& Pfanner, 200I). Note that children were included in this last study only if they had specific difficulties with determiners.

Although school-aged and adolescent French-speaking children with SLI do show differences from their unimpaired peers, especially in elicited production, in domains such as accusative clitic production (Grüter, 2005; Jakubowicz, Nash, Rigaut \& Gérard, I 998; Paradis \& Crago, 2004; Paradis, Crago \& Genesee, 2005/2006), verb inflection (Jakubowicz \& Nash, 200I; Rose \& Royle, I 999), and subject-verb agreement (Franck et al., 2004), the elicitation of verbal and clitic forms is quite difficult in young children and poses interpretation problems, as target production levels are low (see, e.g., Royle \& Elin Thordardottir, 2008). Thus, although Royle and Elin Thordardottir's study reveals differences between groups with and without SLI in elicited verb production, floor effects on the task make the data difficult to interpret. In fact, the younger control children (aged $3 ; 2-4 ; 6$ ) participating in the task might also have been too young to be tested on verb production (Royle, 2007). In the current study, we considered young children's use of noun phrases, which, being acquired early, were expected to provide rich data for our understanding of language acquisition and language impairment.

The noun phrase, also called the determiner phrase (DP), contains determiners and nouns, and can also contain adjective phrases, prepositional phrases, and adjunct structures. Noun phrases are produced in French children's initial utterances (Bassano, 2000; Pannemann, 2007). They quickly become syntactically complex, first containing determiners and even adjectives (with noun-drop). More complex structures (involving a determiner, a noun, and an adjective) emerge between ages 2;0 and 2; 
(Demuth \& Tremblay, 2008; Valois \& Royle, 2009; Valois, Royle, Bourdua-Roy \& Sutton, 2009). Mastery of gender agreement on the determiner is very high throughout $(85-100 \%)$, whereas variable adjective production can take longer, with gender errors often occurring as late as age five years (Roulet-Amiot \& Jakubowicz, 2006; Royle \& Valois, 2010). Although children with SLI typically show relative strengths in the nominal over the verbal domain (Clahsen, I 989; Conti-Ramsden \& Windfuhr, 2002; Le Normand et al., I 993 ; Jakubowicz et al., I998; Rice, Wexler \& Cleave, I 995; van der Lely \& Stollwerck, I 997), studies of nominal acquisition have shown difficulties in number and gender agreement on determiners and adjectives in Spanish (Restrepo \& Gutierrez-Clellen, 200I), case marking in English DPs (Ramos, 2000a), number marking on English nouns (Conti-Ramsden \& Windfuhr, 2002; Goad, I998), and the interpretation and production of definiteness in English (a/the red car) (Ramos, 2000a; 200ob). Italian-, Spanish-, and Swedish-speaking children with SLI also show difficulties with determiners, omitting them at higher rates than control groups in spontaneous production (Bedore \& Leonard, I998; Bottari et al., 200 i Hansson, Nettelbladt \& Leonard, 2003; Leonard et al., 200I ; Paradis et al., 2005/2006) and in probed structures (Hansson et al., 2003; Leonard et al., 2001), all the while not using morphological place holders (usually reduced vowels, e.g. [ə] in [ə'po] standing for /lə〕a'po/ le chapeau 'the hat') to indicate functional positions (Bottari et al., 200 I), a behaviour typically found in normally developing children.

Royle, Toupin, Bourguignon, Trudeau and Valois (2010) elicited DPs in French-speaking children with and without SLI $(8$ children with SLI aged $5 ; 0-5 ; \mathrm{II}$, and four groups of controls aged $3 ; 6-6 ; 0)$ and showed that a majority of children with SLI are more likely to make gender errors on adjective agreement compared to age-matched controls, while a minority also made systematic errors on determiners (omissions and substitutions). However, the question remains as to why DP errors do not surface in the spontaneous speech analyses by Le Normand and colleagues (I993), Elin Thordardottir and Namazi (2007), and Royle and colleagues (2010). It could be that the elicitation task imposes such high cognitive constraints that it results in reduced performance compared to a more natural setting, such as that found in spontaneous speech settings. This is unlikely, however, as the children in Royle et al.'s study showed close to normal performance on a subset of the elicitation tasks, such as colour naming and size DP production, while having more difficulty with complex structures involving colour adjectives and both colour and size adjectives. Alternatively, the spontaneous speech analyses may not provide enough detail about the DP structures for us to gain a better understanding of how they are acquired. Elin Thordardottir and Namazi's study primarily addressed the production and mastery of morphosyntactic markers (mainly verb marking, 
determiners, adjectives, and nominal clitics), and did not analyze the syntactic structures used (i.e. the types of noun or verb phrases) or the morphophonological processes involved in the determiner preposition CONTRACTION, LIAISON and ELISION (see 'Error analysis' and examples therein below). Also, in order to avoid misrepresenting natural language, all adjectives were coded as having gender marking, even though many adjectives in French are invariable (i.e. the feminine and masculine forms are identical). This might have inflated the appearance of gender marking mastery. It is also possible that syntactic and morphosyntactic differences emerge at ages later than those studied by Elin Thordardottir and Namazi. Parisse and Maillart (2007) found differences in 'syntactic' abilities (actually, correct and incorrect use of lexical and function words) in a group of four French-speaking children with SLI with a wider age range ( $3 ; 0-6 ; \circ$, using a longitudinal design). A corpus analysis might be more revealing if a closer look were taken at the variety and complexity of syntactic structures produced by the children, or alternatively, if closer attention were paid to the types of syntactic and morphological errors children make in these structures (e.g. Do children produce contracted determiners such as $d u$ $\left[\mathrm{d}^{\mathrm{z}} \mathrm{y}\right]$ 'of-the.m', an obligatorily contracted form of de le [dələ], or do they produce the uncontracted form?).

It has also been shown that quasi-syntactic measures such as the NUMBER OF THREE-ELEMENT NOUN PHRASES are useful in discriminating between children with and without language impairment (Gavin, Klee \& Membrino, I993), suggesting that syntactic analyses of spontaneous speech data might be helpful in this respect. Furthermore, the mean number of errors in a matrix clause or its subordinate clause has also been found to discriminate between Spanish-speaking children with and without normal language development (Restrepo, I998). Therefore, a finer-grained analysis of syntactic structures used and error patterns appears to be a useful approach to understanding SLI in French pre-school populations.

In the light of different theories of SLI, we developed a number of hypotheses as to what types of difficulties might emerge in the linguistic behaviour of French-speaking children with SLI. According to the first SURFACE HYPOTHESIS ( $\mathrm{SH}$ ) and a later modification, the MORPHOLOGICAL RICHNESS HYPOTHESIS (MR), proposed by Leonard (I998), a general processing deficit, not specific to grammar, will lead children with SLI to focus on language-specific structures that are salient and most relevant to their mother tongue (e.g. English children will focus more on word order to establish thematic roles, whereas Greek children will use case marking to do the same). Leonard does not provide a clear definition of salience, but he often equates this property to morphological richness: the more morphological structure in a given language, the more the child learner will focus on this property and the better and more quickly they will master it. 
Properties such as lexical stress, syllabicity, and sonority are also expected to play a role. Because of the processing deficit in SLI, linguistically less salient structures will be more difficult to master than linguistically more salient ones. French, being a Romance language, has gender agreement in the DP (and elsewhere, e.g. on predicative adjectives, pronouns, and past participle forms). Because gender is a salient grammatical feature, children with SLI should show relative strengths in this domain. However, gender in the DP is most consistently marked on the singular determiner, which is an unstressed clitic (commonly called an article) that is integrated into the foot of the following adjective or noun (Demuth \& Tremblay, 2008), thus rendering it less phonetically salient than free-standing lexical items. Data on acquisition show that French children make few errors in determiner choice (Valois \& Royle, 2009), and omit them at very young ages only when they cannot be footed, e.g. when the words are bisyllabic (Demuth \& Tremblay, 2008) or are part of syntactically complex structures. For example, there are more determiner omissions for la belle pomme 'the nice apple' vs. la banane 'the banana', even though these two contexts have the same number of syllables (Fréchette \& Labelle, 2007). On the other hand, variable adjectives (adjectives with feminine and masculine forms, such as

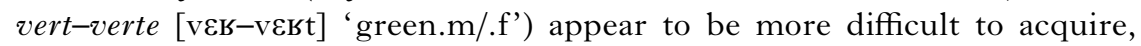
probably due to the highly inconsistent nature of their gender marking (Royle \& Valois, 2010). According to Leonard's approach, French-speaking children with SLI should therefore master determiners relatively well, but show much more difficulty using variable adjectives: no noticeable differences in the syntactic or morphological complexity of DP structure would be expected between different groups of children.

A second hypothesis, developed by Clahsen (I989), proposed that spec-head (noun-verb) agreement is a specific domain of difficulty in children with SLI. His AGREEMENT-DEFICIT (AD) hypothesis would not predict salient difficulties in the DP domain (i.e. head-head Det-N-Adj agreement). However, a more recent version of the AD hypothesis proposes that children with SLI not only have disproportionate difficulties with spec-head agreement, but also with agreement in head-head relationships (within the DP). Ramos (2000a) and Roeper, Ramos, Seymour and Abdul-Karim (200I) proposed that children with SLI might have different DP structures related to specific AGR (agreement) difficulties in multiple domains of syntax (e.g. errors in genitive case marking in the DP, as in Me daddy like mustard, or in nominative case marking, as in Me don't know, as well as in prepositional structures: What beach you going?). Ramos (2000a) showed that English children with SLI (aged $4 ; 9$ to $5 ; 5$ ) can have difficulties understanding and differentiating the meanings of genitive structures such as that bear's balloons (interpreted as 'many bears' balloons' rather than 'one bear with many balloons'), predicative structures such as yellow horse's signs 
(interpreted as 'yellow horse with yellow signs' or 'any horse with yellow signs' rather than 'yellow horse with signs'), and genitive structures such as cat's mug (interpreted as 'cat-shaped mug' rather than 'cat owning a mug') during forced-choice tasks. According to this hypothesis, French children with SLI should show less spontaneous production of complex DPs with structural hierarchies beyond the basic NP, and would also present difficulties involving not only gender marking but also other functional elements such as prepositions and possessive pronouns within the DP.

A third hypothesis as to the nature of difficulties in SLI is the COMPUTATIONAL COMPLEXiTy (CC) hypothesis proposed by Jakubowicz and colleagues (see, e.g., Jakubowicz \& Nash 200I). This hypothesis specifically predicts difficulties related to the level of syntactic complexity of the output. However the underlying grammar is assumed to be intact. Roulet-Amiot and Jakubowicz (2006) studied adjective and determiner production in the French DP in children with SLI aged six and above. They had previously established that French-speaking children mastered the determiner system at the age of four, and that six-year-olds are sensitive to agreement errors during semantic judgement tasks (but see Royle et al., 20 го, for a dissenting opinion on this last point), while adjective agreement mastery occurs around the age of five. According to their study, children with SLI (aged 6 ; IO-I 2 ;6) lag behind their peers, but only in the production of appropriate gender on adjectives (only one example is presented in the article, and it contains both determiner and adjective errors, as well as a syntactic ordering error, *Un *neuf passoire (SLI aged 8;8) 'a.m new.m colander' for une passoive neuve 'a.f colander new.f'). In a second study, Roulet (2007) observed determiner omissions and gender errors in picture naming in a similar group of children with SLI compared to controls aged $6 ; 6$, who made no errors. It must be noted that extreme variability was found in this task, with three children producing the bulk of the errors and only half of the eighteen children with SLI showing abnormal behaviour in terms of agreement errors and omissions. Roulet-Amiot and Jakubowicz (2006) argued that it is the additional syntactic computational complexity of structures with adjectives that makes them more difficult to produce accurately compared to simpler structures (involving, for example only DET-N pairs). Therefore, according to the CC hypothesis, we would expect children with SLI to produce less complex structures than their unimpaired peers. In addition, for structures with low DP complexity (e.g. structures with no adjectives or complements), they should show similar performance to their unimpaired peers, and for structures with greater complexity, they should show more errors.

In summary, the three hypotheses outlined above make different predictions as to the behaviour we should observe in children with SLI: (I) According to the MR hypothesis (Leonard, I998), children with SLI 
should master DP morphosyntax quite well, similarly to unimpaired French speakers. They should show behaviour typical of younger children, such as gender errors on adjectives. (2) According to the AD hypothesis (Ramos, 2000a; Roeper et al., 200I), children with SLI should show difficulties not only with all types of agreement present in the DP (determiners and adjectives, etc.), but also with other structural dependencies such as those found in genitive structures, prepositional phrases, and so on. (3) According to the CC hypothesis (Jakubowicz \& Nash, 200I; Roulet-Amiot \& Jakubowicz, 2006), children with SLI should use simpler syntactic structures than their peers in general, and make more errors in DP-internal agreement only when producing more syntactically complex structures.

To test these hypotheses, we performed an in-depth analysis of DP complexity and error patterns in three groups of children: French-speaking children with SLI and two groups of peers, the first age-matched and the second language-matched with the SLI group. We analyzed syntactic structures used by children with SLI and their peers. Two separate analyses were performed. The first focused on DP structures produced by the children in order to test whether syntactic richness is similar or different in these groups. The second examined error types in order to establish whether the different groups present similar linguistic behaviour with respect to syntactic and morphosyntactic rules governing DP structure.

\section{METHOD}

\section{Participants}

The SLI group consisted of eight monolingual French-speaking children (three girls and five boys) aged between 5 ; 0 and $5 ;$ I I $(M=5 ; 7$ years, $S D=0 ; 4)$ and having a mean length of utterance in words (MLUw) of $4 \cdot 4$ $(S D=0.97)$. These children were recruited through specialized services for children with language impairment (a research hospital and a summer camp), and had been identified by speech language pathologists as having dysphasie (SLI). They had all been in clinical therapy for at least nine months, and had been initially assessed at a minimum nine months and up to three years prior to testing. One pair of children ( $\mathrm{D}_{5}$ and D6) were twins. Additional selection criteria included residing in the province of Quebec, both parents speaking French, being exposed to French at least $80 \%$ of the time at home or in daycare, and having no hearing loss (hearing threshold was set at $20 \mathrm{~dB}$ at $500 \mathrm{~Hz}$, and I $5 \mathrm{~dB}$ at 1000,2000 , and $4000 \mathrm{~Hz}$ for both ears). According to parents' reports, the children presented no history of autism, neurological disorder, hearing loss, learning disabilities, or other medical conditions that could be direct causes of their language impairment.

Each child with SLI was matched with two French-speaking normally developing peers on sex, mean parental education, and MLUw or age 
THE FRENCH NOUN PHRASE

TABLE I. Participant characteristics

\begin{tabular}{|c|c|c|c|c|c|c|c|}
\hline & Age (months) & MLUw & MLUm & Sex & MEM IQ & EVIP & EDUC \\
\hline \multicolumn{8}{|c|}{ SLI group } \\
\hline D2 & 65 & 4.02 & $5 \cdot 18$ & $\mathrm{~F}$ & 109 & $8 \mathrm{I}$ & 22 \\
\hline $\mathrm{D}_{3}$ & 70 & 3.75 & $4.9 I$ & M & 96 & 87 & I 4 \\
\hline $\mathrm{D}_{4}$ & 60 & $2 \cdot 88$ & 3.79 & M & 90 & $<\mathrm{I}$ & $\mathrm{a}$ \\
\hline $\mathrm{D}_{5}$ & 67 & $4 \cdot 39$ & $5 \cdot 79$ & M & 96 & 75 & I I \\
\hline D6 & 67 & $5 \cdot 3^{8}$ & $7 \cdot 17$ & M & 90 & 30 & I I \\
\hline D7 & 69 & $4 \cdot 17$ & $5 \cdot 50$ & M & 106 & I I & I 2 \\
\hline D8 & 69 & $4 \cdot 64$ & $5 \cdot 10$ & $\mathrm{~F}$ & 74 & I 4 & I I \\
\hline D9 & $7 \mathrm{I}$ & $6 \cdot 02$ & 8.06 & $\mathrm{~F}$ & 53 & I 5 & I 4 \\
\hline Mean & $67 \cdot 25$ & $4 \cdot 4 \mathrm{I}$ & $5 \cdot 69$ & & $89 \cdot 0$ & 45 & I 3.6 \\
\hline SD & $3 \cdot 49$ & 0.97 & $\mathrm{I} \cdot 35$ & & I 8 & 35 & $3 \cdot 95$ \\
\hline \multicolumn{8}{|c|}{$A G E$ group } \\
\hline $\mathrm{N}_{55}$ & 63 & $4 \cdot 70$ & $6 \cdot 10$ & $\mathrm{~F}$ & 106 & 79 & I 5 \\
\hline $\mathrm{N}_{50}$ & 69 & $4 \cdot 25$ & $5 \cdot 37$ & M & 122 & 97 & I 4 \\
\hline $\mathrm{N}_{42}$ & $5^{8}$ & $4 \cdot 59$ & $6 \cdot 47$ & M & 103 & 50 & 14.5 \\
\hline $\mathrm{N} 20$ & 67 & $4 \cdot 49$ & $5 \cdot 92$ & $\mathrm{M}$ & I0० & 99 & I 3.5 \\
\hline $\mathrm{N}_{20}$ & 67 & $4 \cdot 49$ & $5 \cdot 92$ & M & 100 & 99 & I 3.5 \\
\hline NioI & 69 & $5 \cdot 27$ & $7 \cdot 3 \mathrm{I}$ & M & IO3 & 97 & I $4 \cdot 5$ \\
\hline Ni 27 & 68 & $3 \cdot 65$ & $5 \cdot 57$ & $\mathrm{~F}$ & I I 2 & 64 & 12 \\
\hline $\mathrm{N}_{9}$ & $7 \mathrm{I}$ & $4 \cdot$ I I & $5 \cdot 77$ & $\mathrm{~F}$ & 100 & 66 & $10 \cdot 5$ \\
\hline Mean & $66 \cdot 25$ & $4 \cdot 44$ & $6 \cdot 05$ & & 106* & $8 I \cdot 4^{*}$ & I $3 \cdot 4$ \\
\hline SD & $3 \cdot 3$ & 0.47 & $0.6 \mathrm{I}$ & & $7 \cdot 72$ & 19.4 & $\mathrm{I} \cdot 5$ \\
\hline \multicolumn{8}{|c|}{$M L U$ group } \\
\hline $\mathrm{N} 62$ & 49 & $4 \cdot 03$ & 5.03 & $\mathrm{~F}$ & 87 & $5^{8}$ & I 3.5 \\
\hline N96 & 45 & $3 \cdot 87$ & $4 \cdot 64$ & M & I06 & 68 & IO \\
\hline Ni9 & 38 & $3 \cdot 15$ & $4 \cdot 28$ & M & 84 & 94 & I $6 \cdot 5$ \\
\hline $\mathrm{N}_{4} \mathrm{I}$ & $5^{6}$ & $4 \cdot 28$ & $5 \cdot 7 \mathrm{I}$ & $\mathrm{M}$ & I09 & 50 & I3 \\
\hline Ni 5 & 49 & $5 \cdot 6 \mathrm{I}$ & $7 \cdot 5 \mathrm{I}$ & M & 125 & 50 & I 5 \\
\hline N8o & 46 & $4 \cdot 2 \mathrm{I}$ & $5 \cdot 66$ & M & 122 & 73 & I 2 \\
\hline $\mathrm{N}_{92}$ & 43 & $4 \cdot 2 \mathrm{I}$ & $5 \cdot 56$ & $\mathrm{~F}$ & I 43 & 62 & I 5.5 \\
\hline $\mathrm{N}_{3}$ & 44 & $6 \cdot 15$ & $7 \cdot 77$ & $\mathrm{~F}$ & 87 & 30 & I4 \\
\hline Mean & $46 \cdot 25 * *$ & $4 \cdot 43$ & $5 \cdot 77$ & & I09! & $60 \cdot 6 !$ & I $3 \cdot 7$ \\
\hline $\mathrm{SD}$ & $5 \cdot 29$ & 0.96 & $I \cdot 26$ & & $2 \mathrm{I}$ & I $8 \cdot 9$ & 2.07 \\
\hline
\end{tabular}

NOTES: a: missing value.

MLUw: mean length of utterance in words; MLUm: mean length of utterance in morphemes.

MEM IQ: Leiter memory subtest.

EVIP: French PPV'T receptive vocabulary, centile score.

EDUC: mean parental education.

T-tests between SLI and control groups: ! $p<0 . \mathrm{I}, * p<0.05$, ** $p<0.0 \mathrm{I}$.

(depending on the group) to create a triad for analyses. Individual participant characteristics are presented in Table $\mathbf{I}$. The MLU-matched group had a mean age of $3 ; 09(S D=0 ; 6)$ and a MLUw of $4.67(S D=0.87)$. The AGE-matched group had a mean age of $5 ; 6(S D=0 ; 3)$ and a MLUw of 4.4 $(S D=0 \cdot 47)$. These children were chosen from a larger sample of over $5_{50}$ children participating in a project aimed at developing norms for a DP production task (Royle, 2005-2008). Selection criteria for both groups were 
the same as for the SLI group, excluding SLI diagnosis. Significant differences were observed between SLI and the AGE-matched group on the LEITER memory screen and the EVIP vocabulary score. As expected, a significant difference in age was observed between the SLI and the MLU-matched group. No significant differences were observed between SLI and control groups on MLU scores (however, these scores did not include morpheme counts). This is not unheard of in studies of SLI in French speakers (Elin Thordardottir et al., 2005; Elin Thordardottir \& Namazi, 2007).

\section{Procedure}

Participants and their parents were invited to an experimental session lasting approximately one-and-a-half hours and held in a recording lab equipped with an observation post (two-way mirror) at the Centre de recherche MarieEnfant (Montreal, Canada). The procedure was approved by the IRB committee of Centre de recherche CHU Ste-Fustine. Parents signed a consent form for their child's participation. The children were assessed with a number of linguistic and cognitive tasks: a hearing screening, an assessment of receptive vocabulary in French (EVIP, Échelle de vocabulaire en images Peabody; Dunn, Thériault-Whalen \& Dunn, I993), a non-verbal memory IQ task (Leiter Memory Screen; Roid \& Miller, I996), an experimental elicitation of noun phrase structures with adjectives (Royle \& Valois, 2010; Royle et al., 2010), and a spontaneous speech recording used to analyze morphosyntactic structures of interest and to establish mean length of utterance in words (MLUw) and morphemes (MLUm). Only spontaneous speech data are presented here. Table I shows EVIP, IQ, and MLU scores as well as parental education levels for all groups. Audio-video recordings were made of the spontaneous speech samples. Non-directive speech was used by research assistants while individual children played with a standard set of toys (play dough, cooking utensils, dinosaurs). Parents were asked not to interact orally with the children during the procedure. They could observe the procedure through a two-way mirror or sit with the child if he or she was too shy to stay alone with the experimenter.

Because complex DP structures are relatively rare in spontaneous speech, a minimum of 200 utterances were obtained for each child (Valois \& Royle, 2009). These were coded using the SALT program (Systemic Analysis of Language Transcripts; Miller and Chapman, I984-2002) adapted to French (Elin Thordardottir et al., 2005). MLU counts in morphemes and words were based on a sample of the first i oo utterances. Spontaneous speech was transcribed by the same research assistants who administered the tasks. Control participants' transcriptions had already been checked in a four-step process. Each transcription was checked by a second native speaker, then 
coded for morphosyntax and checked again. All disagreements were resolved by consensus. When no consensus was obtained, the transcriptions were coded as incomprehensible ( $<\mathrm{I} \%$ of the total). The first author checked for reliability by retranscribing the entire SLI corpus transcribed by the second author. An initial analysis of reliability revealed that both transcribers heard the same words $96 \cdot 6 \%$ of the time. Most divergences occurred when one transcriber heard a word whereas the other did not. We also checked for inter-transcriber morpheme reliability. For all the words that both transcribers heard, we checked whether they had transcribed the same inflectional or root morpheme. Inter-transcriber reliability on this measure was $97 \cdot 9 \%$. Spontaneous speech corpora were similar in length for all groups, and the first 200 utterances were analyzed for each child.

The corpora were then analyzed to identify all DPs produced. A total of 3049 DPs were included in the analysis. Between 7I and I7I DPs were produced by each child $(M=\mathrm{I} 27, S D=29 \cdot 66)$. Each noun was considered along with its determiner and other lexical or syntactic structures, if present within the DP. In addition, the use of prepositions de 'of' and à 'to' were analyzed when they occurred DP-initially, because they are part of the complex contracted determiners $d u$ and $d e$ la 'of the.m/f', des 'of the.m/f.pl', $a u$ and à $l a$ 'to the.m/f', and $a u x$ 'to the.m.pl/f.pl'. Moreover, $d u$ and de la are the determiners used for mass nouns (du pain 'bread', de la bière 'beer'). Paralexemes, ${ }^{1}$ a common compound type in French that contains a prepositional structure (e.g. maison de poupée, 'doll house', literally 'house of doll'), were counted as one lexical unit in the coding system (see Elin Thordardottir et al., 2005). When a DP contained an unintelligible element or a word used ambiguously, it was excluded from the analysis. On average, $3 \cdot 2 \mathrm{I}$ DPs per child $(S D$ 2.28, Min=o, Max = Io) were excluded from the analysis.

\section{Syntactic analysis}

All DPs were classified according to syntactic structure type: determiner + noun (DN, (Ia)), proper noun $(\mathrm{PN},(\mathrm{Ib}))$, determiner + noun + adjective

[I] Paralexemes can be identified using the following linguistic tests: (I) they bear only one word-final lexical stress, rather than two or more; (2) they are inseparable (e.g. maison de *grosse poupée, 'house of big doll', in the sense of 'doll house'); (3) they can often be replaced with morphologically simple synonyms (e.g. pomme de terre, literally 'apple of earth' = patate 'potato'); (4) one cannot change part of the paralexeme for a synonym while preserving meaning (e.g. *MacIntosh de terre 'MacIntosh of the earth'); (5) coordination is impossible within them (*maison de soldat et de poupée 'soldier and doll house'); and (6) they must be complete in anaphoric structures, contrary to noun phrases with PP complements, where the noun alone can be repeated (e.g. F'avais un seau de terre et des pommes de terre. F'ai perdu le seau mais pas les *pommes. 'I had a bucket of earth and some potatoes. I lost the bucket but not the apples'). 
(DNA, (Ic)), determiner + noun + prepositional phrase (DNP, (Id)), noun-drop (NDrop, ( I e)), preposition + noun (with or without a determiner, PrepN, (If)), and Other (Ig). We identified the DP's head noun gender (masculine, feminine) and noted additional words or syntactic structures they contained (adjective, adverb, coordinate clause, preposition, quantifier, relative clause, verb) as well as the presence of determiners, noun-drop, grammatically correct omission of the determiner (e.g. rose 'pink' as an answer to "What is your favourite colour?"), proper nouns, and other elements that were present. All productions were coded for any errors present (see 'Error analysis' below). The number of occurrences of the different DP types, the number of feminine and masculine DPs, and the number of simple DPs (i.e. DPs containing a noun and a determiner (DN), a proper noun $(\mathrm{PN})$, or a noun introduced by a preposition (PrepN)) versus complex DPs (all other types) were also calculated for each child.
a. un chien
$\mathrm{DN} \quad(\mathrm{D} 2,5 ; 5)$
'a.m dog'
b. grandpapa Gilles
$\mathrm{PN} \quad(\mathrm{D} 2,5 ; 5)$
'grandpa Gilles'
c. un bouchon vert
DNA $\left(\mathrm{D}_{2}, 5 ; 5\right)$
'a.m plug green.m'
d. les arbres (dans les arbres) dans les branches $\quad$ DNP (D2, 5; 5)
'the trees (in the trees) in the branches'
e. la rouge
NDrop $\left(\mathrm{D}_{2}, 5 ; 5\right)$
'the.f red (one)'
f. d'place
of-room = 'space/room' (mass)
$\operatorname{PrepN}\left(\mathrm{D}_{2}, 5 ; 5\right)$
g. un truc qui fait d'lumière en haut
Other $\left(\mathrm{D}_{2}, 5 ; 5\right)$
'a thing to make of light on up'= something to make light up there

\section{Error analysis}

Error types were classified and coded as ungrammatical (UG) - these included structures with more than one syntactic or morphosyntactic error (2a), insertion (IN, (2b)), substitution (S, (2c)), word order (WO, (2d)), gender or number agreement (AGR, (2e-f)), omission (OM, (2g)), and over-regularization (OR, $(2 \mathrm{~h}-\mathrm{k}))$. Over-regularization errors included contraction ( $2 \mathrm{~h}$ ), liaison (2i), elision (2j), and lexical errors (2k) with irregular plurals or idiosyncratic adjectives.

(2) a. des princesses les barbies

UG (Do9, 5; I I)

'some princesses the Barbies'= the Barbie princesses

b. de l'ami=l'ami

IN $\left(\mathrm{No}_{3}, 3 ; \circ 8\right)$

'of the-friend' $=$ the friend 
c. des chevaux=les chevaux

'some horses' = 'the horses'

d. méchant un gros requin $=$ un gros requin méchant $\mathrm{WO}\left(\mathrm{D}_{5}, 5 ; 7\right)$ ' mean.m a.m big.m shark' = a big mean shark

e. la vert 'the.f green.m (one)'

$\operatorname{AGR}\left(\mathrm{D}_{2}, 5 ; 5\right)$

f. les petits choses qui plein de couleur 'the.pl small.m things that full of colour'

g. - porte

h. à les dinosaures $=$ aux dinosaures 'of-the dinosaurs' AGR (Do9, 5; I I)

i. le nenfant = l'enfant

$\mathrm{OM}(\mathrm{D} 2,5 ; 5)$ 'the child'

j. des drôles de images [dœ.ima3]=d'images [dima3] 'some funny (of) images'

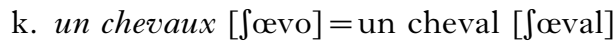
'a horses' = 'a horse'

OR Contraction

(N5o, 5;9)

OR Liaison

(D), 6; ro)

OR Elision

(N55, 5;3)

OR Lexeme

(Ni I 5, 4; I)

The first three types of OR are linked to highly productive phonological rules of French, and the fourth is lexical. The first, in (2h), illustrates the absence of preposition and determiner contraction (an obligatory process in French). The child produced the full phonological form of the preposition and the determiner (à les [a.le]) instead of the standard fused form (aux [o]). The second error type is the interpretation of liaison as being part of the word structure (2i). In French liaison, the final consonant in $u n$ and des and other determiners are pronounced only if the following word starts with a vowel (i.e. it has an empty syllable onset and the determiner is syllabified into the phonological word, e.g. un enfant [oẽnãfã] 'a child' vs. un papa [oẽpapa] 'a father'). In the early stages of acquisition, French-speaking children can mis-analyze vowel-initial words (such as enfant in (2i)) as having a consonant onset and produce these liaisons in spontaneous speech (see, e.g., Chevrot \& Fayol, 200I, and Wauquier-Gravelines \& Braud, 2005, for a description of this behaviour in children aged from $\mathrm{I} ; 4$ to 4 ; 0 and elicitation in ages 3 ; 0 to 4;5). Liaison errors are not typical of children older than four (see Chevrot \& Fayol, 200 I, for experimental support) and peak at around age 3;5 (Wauquier-Gravelines \& Braud, 2005). A third type of error was linked to elision $(2 \mathrm{j})$, or phonological reduction on a vowel-final determiner when it is followed by a vowel-initial word. Here the child produced the full determiner [dœ.ima3] 'of images' instead of the elided form [dima3] 'of-images'. The fourth type of over-regularization (2k) was the substitution of a wrong lexeme for another (usually an irregular singular 
or plural form) when the noun had both singular and plural forms. In French, the default and regular rule for plural involves no change between the singular and plural (i.e. chat 'cat.s' and chats 'cat.pl' are both pronounced [ $\left.\int \mathrm{a}\right]$ ). A subgroup of nouns ending in -al and -ail have -aux plurals (see, e.g., (2k), where the child used the irregular plural instead of the singular form of horse). Because the regular rule of French pluralization involves NO MORPHOLOGICAL OR PHONOLOGICAL CHANGE, and children appear to be applying this regularity to irregular forms, we classified these errors as over-regularizations.

When a child made more than one error on a single lexeme, both errors were described, but it was considered as one error only in the statistical analysis when the target involved contraction. This was done to avoid inflating error statistics when tallying forms with contracted prepositions and determiners. For example, although the DP les choses à bébé 'the things of baby', for les choses du bébé 'the things of-the baby' = 'the baby's things', contains a preposition substitution ( $a$ ' to' instead of $d \mathrm{e}^{\text {' }}$ of') and a determiner omission (le 'the'), only one error (substitution) was tallied, as the target is a contracted form.

\section{RESULTS}

Because we used non-parametric statistical analysis, only DP structures accounting for at least $5 \%$ of the all DPs from the triads (children with SLI and their two matched control groups) were considered in order to obtain statistically valid comparisons. Due to the large variability in complex structures used, most complex structures did not meet this criterion, and were grouped into the category 'Other'. Frequencies for syntactic structures and error patterns were entered into separate chi-square analyses comparing SLI children and control groups. An alpha of 0.05 was used for all analyses. We first present the data on syntactic structures, followed by the error analysis.

\section{Syntactic structures}

When comparing all syntactic structures used, we observed significant differences between SLI and AGE groups $\left(\chi^{2}(6, N=2\right.$ I27 $)=20 \cdot 8$ I, $p<0.0 \mathrm{I})$ as well as MLU groups $\left(\chi^{2}(6, N=\mathrm{I} 969)=\mathrm{I} 7.94, p<0.0 \mathrm{I}\right)$. Although all groups preferred simple DPs (DN, PN, and PrepN structures), other preferences emerged in the comparisons (see Tables 2 and 3 for a breakdown of structures used by the three groups).

As can be seen, the proportions of DP types produced varied according to group. The SLI group produced fewer PrepN, NDrop, DNP, and Other structures but more DN and PN structures than the AGE group. When 
TABLE 2. Frequency of syntactic structures for determiner phrases in SLI and AGE groups

\begin{tabular}{|c|c|c|c|}
\hline \multirow[b]{2}{*}{ Syntactic structures } & \multicolumn{2}{|c|}{ Group } & \multirow[b]{2}{*}{ Total } \\
\hline & SLI & AGE & \\
\hline \multicolumn{4}{|l|}{$D N$} \\
\hline Observed & $646(6 \mathrm{I} \cdot 7 \%)$ & $642(59 \cdot 4 \%)$ & I 288 \\
\hline Expected & 634 & 654 & \\
\hline \multicolumn{4}{|l|}{$P N$} \\
\hline Observed & $90(8 \cdot 6 \%)$ & $57(5 \cdot 3 \%)$ & I 47 \\
\hline Expected & $72 \cdot 4$ & $74 \cdot 6$ & \\
\hline \multicolumn{4}{|l|}{$D N A$} \\
\hline Observed & I $23($ I I $· 7 \%)$ & I $26($ I I $7 \%)$ & 249 \\
\hline Expected & I $22 \cdot 6$ & $\mathrm{I} 26 \cdot 4$ & \\
\hline \multicolumn{4}{|l|}{ PrepN } \\
\hline Observed & $42(4 \cdot 0 \%)$ & $54(5 \cdot \circ \%)$ & 96 \\
\hline Expected & $47 \cdot 3$ & $48 \cdot 7$ & \\
\hline \multicolumn{4}{|l|}{ NDrop } \\
\hline Observed & $54(5 \cdot 2 \%)$ & $68(6 \cdot 3 \%)$ & 122 \\
\hline Expected & $60 \cdot I$ & $6 I \cdot 9$ & \\
\hline \multicolumn{4}{|l|}{$D N P$} \\
\hline Observed & $30(2 \cdot 9 \%)$ & $59(5.5 \%)$ & 89 \\
\hline Expected & $43 \cdot 8$ & $45 \cdot 2$ & \\
\hline \multicolumn{4}{|l|}{ Other } \\
\hline Observed & $62(5 \cdot 9 \%)$ & $74(6 \cdot 9 \%)$ & I 36 \\
\hline Expected & $66 \cdot 9$ & $69^{\circ} \mathrm{I}$ & \\
\hline Total & I047 & 1080 & \\
\hline
\end{tabular}

NOTES: DN: determiner+noun; PN: proper noun; DNA: determiner + noun + adjective; PrepN : preposition $+(\mathrm{det})$ + noun; DNP determiner + noun + preposition; NDrop: noundrop.

comparing the SLI and MLU groups, children with SLI again produced more DN and PN structures in addition to more DNA and NDrop structures than MLU controls. However, they produced only slightly fewer PrepN and Other structures than controls. Given the small sample sizes, we compared the SLI and control groups' production of each structure using the Wilcoxon signed rank test with an alpha of 0.05 . Only one result showed group differences: SLI children produced more DNA structures $\left(M d n=\mathrm{I}_{5} \cdot 6\right.$, Range $\left.=7 \cdot 2\right)$ than MLU controls $(M d n=9 \cdot 75$, Range $=4 \cdot 5)$ $(z=(8)-2 \cdot 38, p=0 \cdot 02)$. The difference in proper noun use between SLI and AGE groups also failed to reach significance $(p>0 \cdot I)$, and appears to be linked to two children's over-reliance (D5 and D8, with 33 and 29 proper nouns each in their respective corpora) on this specific structure.

Regarding individual results, we noted that most AGE control children produced at least four examples of the analyzed structures. Only two AGE controls produced a single proper noun, while another produced only three 
TABLE 3. Frequency of syntactic structures for determiner phrases in SLI and MLU groups

\begin{tabular}{|c|c|c|c|}
\hline \multirow{2}{*}{$\begin{array}{l}\text { Syntactic } \\
\text { structures }\end{array}$} & \multicolumn{2}{|c|}{ Group } & \multirow[b]{2}{*}{ Total } \\
\hline & SLI & MLU & \\
\hline \multicolumn{4}{|l|}{$D N$} \\
\hline Observed & $646(6 \mathrm{I} \cdot 7 \%)$ & $609(66 \cdot$ I \%) & I 255 \\
\hline Expected & $667 \cdot 3$ & 587.7 & \\
\hline \multicolumn{4}{|l|}{$P N$} \\
\hline Observed & $90(8 \cdot 6 \%)$ & $54(5 \cdot 9 \%)$ & I 44 \\
\hline Expected & $76 \cdot 6$ & $67 \cdot 4$ & \\
\hline \multicolumn{4}{|l|}{$D N A$} \\
\hline Observed & I $23($ I I $77 \%)$ & $78(8 \cdot 5 \%)$ & 201 \\
\hline Expected & Iо $6 \cdot 9$ & $94 \cdot \mathrm{I}$ & \\
\hline \multicolumn{4}{|l|}{ PrepN } \\
\hline Observed & $42(4 \cdot \circ \%)$ & $57(6 \cdot 2 \%)$ & 99 \\
\hline Expected & $52 \cdot 6$ & $46 \cdot 4$ & \\
\hline \multicolumn{4}{|l|}{ NDrop } \\
\hline Observed & $54(5 \cdot 2 \%)$ & $37(4.0 \%)$ & $9 \mathrm{I}$ \\
\hline Expected & $48 \cdot 4$ & $42 \cdot 6$ & \\
\hline \multicolumn{4}{|l|}{$D N P$} \\
\hline Observed & $30(2 \cdot 9 \%)$ & $27(2.9 \%)$ & 57 \\
\hline Expected & $30 \cdot 3$ & $26 \cdot 7$ & \\
\hline \multicolumn{4}{|l|}{ Other } \\
\hline Observed & $62(5.9 \%)$ & $60(6 \cdot 5 \%)$ & 122 \\
\hline Expected & 649 & $57^{\circ} \mathrm{I}$ & \\
\hline Total & I047 & 922 & \\
\hline
\end{tabular}

NOTES: DN: determiner + noun; PN: proper noun; DNA : determiner + noun + adjective; PrepN : preposition + (det) + noun; DNP determiner + noun + preposition; NDrop: noundrop.

PrepN and two children produced fewer than four Other structures. Children with SLI and their MLU controls showed less consistency in their behaviour: a minimum of two (and up to four) children with SLI produced fewer than four instances of every analyzed type, except for DN and DNA noun phrases. MLU controls showed similar behaviour, with a minimum of one (and up to three) children producing fewer than four instances of a given structure, again except for DN and DNA types.

Because we were interested in knowing whether structural complexity was driving these group differences, we grouped all DP types into simple versus complex structures and reran the chi-square analyses. Simplex structures were proper nouns (PN), determiner-noun (DN), and preposition-noun structures (PrepN) involving no extra elements apart from obligatory ones. All other structures involving additional elements such as adjectives, prepositional phrases, relative clauses, and so on were considered to be complex. This was also the case for noun-drop structures 
(NDrop), which are assumed to contain an adjective phrase (Valois \& Royle, 2009). Results confirmed significant differences between SLI and AGE groups $\left(\chi^{2}(\mathrm{I}, N=2027)=5 \cdot 54, p<0.02\right)$, and between SLI and MLU groups $\left(\chi^{2}(\mathrm{I}, N=\mathrm{I} 969)=3.86, p=0.05\right)$. Children with SLI produced fewer complex structures $(269$, or $25.7 \%$ of structures) on average than the AGE group $(327$, or $30.3 \%$ ), and more of these on average than the MLU group (with 202 , or $2 \mathrm{I} \cdot 9 \%$ of structures).

In sum, our syntactic analyses of DPs revealed subtle differences between control and SLI groups. The main difference was that AGE-matched children produced more complex structures than their peers with SLI. This difference went in the opposite direction when comparing SLI and MLU-matched groups, indicating that it is difficult to distinguish between children with language impairment and normally developing children using these syntactic measures.

A closer look at the complex structures produced by SLI and control groups confirms that the differences between the groups are subtle. DPs with noun-drop (NDrop) were not systematically produced by SLI and MLU groups. DPs with relative clauses were more common in the AGE group, where six children produced between one and ten, with other children (SLI and AGE) producing fewer of these. DPs with adverbs were uncommon overall, and were inconsistently produced by the SLI and MLU groups. Coordinate DPs were used by subsets of the SLI group ( D $_{5}, \mathrm{D}_{7}$, D8, and D9) and MLU children (N62, Ni ${ }_{5}, \mathrm{~N}_{92}$, and $\mathrm{N}_{3}$ ), whereas only two AGE-controls produced any $\left(\mathrm{N}_{55}\right.$ and $\left.\mathrm{N}_{9}\right)$. Other structures we will call expansions were produced by all groups. Examples are presented in (3). Children with SLI produced $5 \cdot 9$ of these on average $\left(S D D_{3} \circ\right.$, range I-IO), whereas the AGE-matched group produced 9.75 (SD 3.0, range 4-I 8$)$ and the MLU-matched group $4 \cdot 63$ on average ( $S D \quad 2 \cdot 9$, range $0-9)$. These expansions contained genitive structures, always introduced by the preposition $d e$ in French (3a), complement phrases introduced by prepositions $(3 \mathrm{~b})$, DPs introduced by prepositions $(3 \mathrm{c})$ (similar in structure to the above-discussed paralexemic compounds), and more rarely, infinitive complements, again within prepositional phrases $(3 \mathrm{~d})$.

(3) a. les monstres de Scooby Doo

Ni I $5(4 ;$ I $)$

the.pl monsters of Scooby Doo= 'the Scooby Doo monsters'

b. des parties où c'est pas solide

N2o $(5 ; 7)$

some parts where it-is not solid = 'parts that aren't solid'

c. des tours d'éléphant

N9 $(5 ;$ I I $)$

some tours of-elephant = 'elephant rides'

d. l'heure d'aller faire la sieste pour moi $\quad \mathrm{N}_{42}$ (5; 10) the-time to-go.INF do.INF the nap for me= "time for me to go have a nap' 


\begin{tabular}{|c|c|c|c|}
\hline \multirow[b]{2}{*}{ Syntactic structures } & \multicolumn{2}{|c|}{ Group } & \multirow[b]{2}{*}{ Tota } \\
\hline & SLI & $\mathrm{AGE}$ & \\
\hline \multicolumn{4}{|l|}{ Agreement } \\
\hline Observed & $27(18 \%)$ & I $4(24 \cdot I \%)$ & $4 \mathrm{I}$ \\
\hline Expected & $29 \cdot 6$ & I I $\cdot 4$ & \\
\hline \multicolumn{4}{|l|}{ Omission } \\
\hline Observed & $75(50 \cdot 0 \%)$ & I $5(25.9 \%)$ & 90 \\
\hline Expected & $64 \cdot 9$ & $25 \cdot I$ & \\
\hline \multicolumn{4}{|l|}{ Substitution } \\
\hline Observed & $38(25 \cdot 3 \%)$ & I3 $(22 \cdot 4 \%)$ & $5 \mathrm{I}$ \\
\hline Expected & $36 \cdot 8$ & I $4 \cdot 2$ & \\
\hline \multicolumn{4}{|l|}{ Over-regularization } \\
\hline Observed & Io $(6 \cdot 7 \%)$ & I6 $(27 \cdot 6 \%)$ & 26 \\
\hline Expected & I $8 \cdot I$ & $7 \cdot 3$ & \\
\hline Total & I 50 & $5^{8}$ & \\
\hline
\end{tabular}

\section{Error patterns}

Three error types (ungrammatical (UG), insertion (IN), and word order (WO)) had fewer than five instances per group (IN reached six items in the SLI group only) and were excluded from the statistical analysis. The remaining four error types (agreement (AGR), substitution (S), omission (OM), over-regularization (OR)) were included in the analyses. The distribution of the SLI group was significantly different from that of the AGE group $\left(\chi^{2}(3, N=208)=2 \mathrm{I} \cdot 22, p<0 \cdot 00 \mathrm{I}\right)$ and the MLU group $\left(\chi^{2}(3, N=23 \mathrm{I})=\mathrm{I} 4.22, \quad p<0.0 \mathrm{I}\right)$ in its error patterns. Error type frequencies for the three groups are presented in Tables 4 and 5 .

As presented in Table 4, children with SLI made more OM, S, and AGR errors and fewer OR errors than both control groups. We compared the SLI and control groups' production of each error type using the Wilcoxon signed rank test with an alpha of 0.05 . The differences in OM errors between SLI and AGE groups were significant: SLI $(\mathrm{Mdn}=7$, Range $=\mathrm{I} 8$ ) vs. the AGE group $\left(\operatorname{Mdn}=\mathrm{I}_{5} \cdot 5\right.$, Range $\left.=4\right)(\mathrm{z}=(8)-2 \cdot 4 \mathrm{I}, p<0 \cdot 02)$, and vs. the MLU group $(\mathrm{Mdn}=3.5$, Range $=\mathrm{I} 6)(z=(8)-2.2 \mathrm{I}, p<0.05)$. S errors were also significantly more common in the SLI group ( $\operatorname{Mdn}=4.5$, Range $=7)$ than in the AGE $(\mathrm{Mdn}=2$, Range =4) $(z=(8)-2 \cdot 34, p<0.02)$ and MLU groups $(\operatorname{Mdn}=\mathrm{I}$, Range=3) $(z=(8)-2 \cdot 32, p=0.02)$. The differences in other error patterns did not reach significance.

What appears to distinguish the SLI and control groups is omission and commission (substitution) of obligatory elements. All children with SLI produced at least 3 and up to $2 \mathrm{I}$ omissions (average $9 \cdot 4$ ), whereas AGE-matched controls produced from $\circ$ to 4 of these types (average $1 \cdot 9$ ), 


\begin{tabular}{|c|c|c|c|}
\hline \multirow[b]{2}{*}{ Syntactic structures } & \multicolumn{2}{|c|}{ Group } & \multirow[b]{2}{*}{ Total } \\
\hline & SLI & MLU & \\
\hline \multicolumn{4}{|l|}{ Agreement } \\
\hline Observed & $27(18.0 \%)$ & II $($ I $3 \cdot 6 \%)$ & 38 \\
\hline Expected & $24 \cdot 7$ & I3.3 & \\
\hline \multicolumn{4}{|l|}{ Omission } \\
\hline Observed & $75(50 \cdot 0 \%)$ & $43(53 \cdot 1 \%)$ & II 8 \\
\hline Expected & $76 \cdot 6$ & $4 \mathrm{I} \cdot 4$ & \\
\hline \multicolumn{4}{|l|}{ Substitution } \\
\hline Observed & $38(25 \cdot 3 \%)$ & IO $(12 \cdot 3 \%)$ & 48 \\
\hline Expected & $3 I \cdot 2$ & I $6 \cdot 8$ & \\
\hline \multicolumn{4}{|l|}{ Over-regularization } \\
\hline Observed & Io $(6 \cdot 7 \%)$ & I7 $(2 \mathrm{I} \cdot 0 \%)$ & 27 \\
\hline Expected & I $7 \cdot 5$ & $9 \cdot 5$ & \\
\hline Total & I 50 & $8 \mathrm{I}$ & \\
\hline
\end{tabular}

and MLU controls were more variable, producing from $\circ$ to 16 omissions (average 5.4). It is important to note that the most common error in both the MLU and SLI groups was the omission of obligatory elements, but that these errors occurred significantly more often in the SLI group. Substitutions were also a hallmark of the SLI group, which produced 4.8 (range $\mathrm{I}-8$ ) of these on average, compared to $\mathrm{I} \cdot 6$ (range $0-4$ ) for the AGE group and $\mathrm{I} \cdot 3$ (range $0-3$ ) for the MLU group. On the other hand, lexemic over-regularization, i.e. using inappropriate lexemes (noun or adjective) with irregular plural or variable masculine forms (e.g. cheval/chevaux 'horse/s', animal/animaux 'animal/s', oeuf [œf]/oeufs [ø] 'egg/s', beau/bel' 'handsome.m') were found in a minority of children (one SLI child, and two each in the AGE and MLU matched groups), but were more frequent in controls.

Finally, it should be noted that children with SLI produced a number of insertions. Because these errors were rare in control groups ( 2 in each group), they were excluded from the analyses. They included the insertion of an ou 'or' between the (gender inappropriate) determiner and the noun (4a), insertion of an uncontracted preposition and determiner (genitive structure) between the adjective and the noun (4b), insertion of the $3 \mathrm{ps}$ masculine clitic pronoun $i$ (the reduced form of $i l$ 'he') in the DP (4c), insertion of a genitive preposition in a nominative structure $(4 \mathrm{~d})$, and insertion of a singular definite determiner when the context requires either

[2] This form appears before vowel-initial masculine nouns and is homophonous with the feminine belle. 
a plural indefinite or, more commonly, no determiner (4e; note that this example also contains a common verb over-regularization sontaient, which is used in many dialects of Quebec French). These appear to signal insensitivity to syntactic constraints on DP structure.

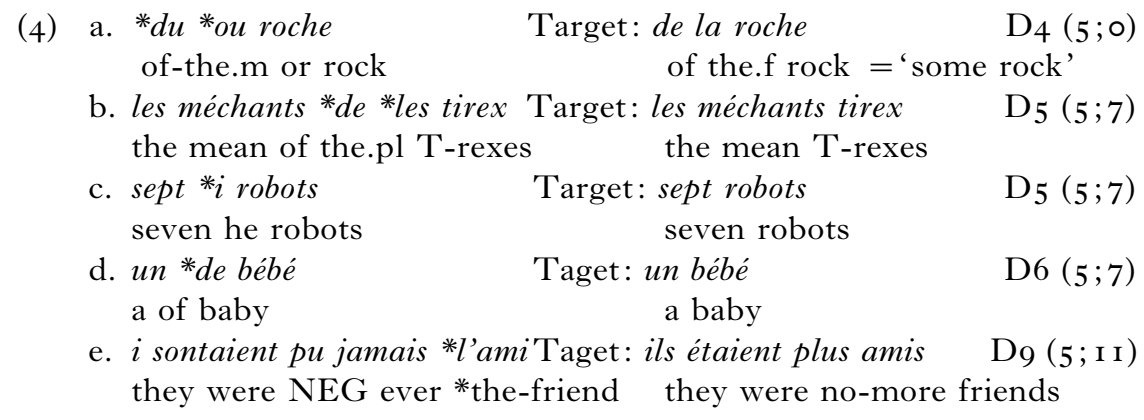

\section{ISCUSSION}

The data presented here show that children with SLI aged 5; 0 to 5; I presented both subtle and straightforward differences from their peers in DP production abilities. Generally, we can characterize their syntactic profile as somewhere between their age-matched and the younger (MLU-matched) peers. Children with SLI gravitated towards a simpler DP syntax compared to AGE-matched controls. Their linguistic productivity appeared to be more constrained than that of normally developing children, and was in many respects similar to that of MLU-matched peers.

Although there were generally few errors in the corpus, the error analyses further distinguished the three groups. The SLI children stood out in their propensity to omit and to substitute obligatory elements in the DP. Omissions accounted for $50 \%$ of their errors (versus $25.9 \%$ for the AGE group). However, these were also the most frequent error type in the MLU group, accounting for $53 . \mathrm{I} \%$ of errors. Substitutions, the second most common error type in the SLI group $(25.3 \%)$, were rarer in both the AGE and MLU groups, accounting for $12 \cdot 3 \%$ of errors in the MLU group and $\mathbf{2 2} .4 \%$ of errors in the AGE group. Insertion errors were found only in the SLI group, pointing to a marker that could be helpful for identifying SLI in young French speakers. However, these error types were also relatively rare, and were observed in only half the children with SLI.

Previous elicitation research suggests that agreement errors are a salient aspect of language difficulties in French SLI (Roulet, 2007; Roulet-Amiot \& Jakubowicz, 2006; Royle et al., 2010). This did not turn out to be the case in the spontaneous speech data. Although children with SLI made more agreement errors on average than controls, these differences did not reach

$$
964
$$


significance. A more encompassing study of all types of agreement in the corpus (e.g. clitics and predicative adjectives) might obtain richer data on agreement, but that was beyond the scope of this study.

Over-regularization patterns also appeared to differ across the three groups. In the children studied here, the absence of contraction and the presence of liaison errors appeared to signal an immature grammar. On the other hand, lexemic over-regularization errors involving the use of default no-change forms appeared to be the domain of normally developing children. In sum, children with SLI might also have difficulties with the automatic application of morphophonological rules at ages when unimpaired children do not normally show this behaviour.

One should bear in mind that this study examined a small sample of children, and that the observed linguistic behaviour may not be generalizable to the entire population of French-speaking children with SLI. One must also take into account that the children in this study were classified as light to severe SLI, and might have shown variable levels of difficulty, in terms of either language production or comprehension. Regarding the diagnostics used to identify children with SLI in Quebec, it is unclear whether these children would have been identified as late talkers rather than having SLI in other circumstances, given the strict criteria for the dysphasie diagnosis (see 'Introduction' and 'Participants' above). We remain confident that these children are representative of French children with SLI.

\section{Theories of SLI}

The fact that children with SLI tended to produce more syntactically simple DP structures than their peers goes against the MC hypothesis (Leonard, I998), according to which children with SLI should master DP syntax, even though they might have difficulties with variable adjectives, and unstressed elements in the DP such as determiners. Results support both the AD hypothesis (Roeper et al., 200I) and the $\mathrm{CC}$ hypothesis (Roulet-Amiot \& Jakubowicz, 2006), because these two approaches predict reduced structures in language production. However, according to Roulet-Amiot and Jakubowicz, children with SLI should show similar performance to their peers (i.e. without errors) when producing syntactically simple DPs. This was not the case, as they produced $52 \%$ of their errors on simple structures (usually omissions, substitutions, or, les often, liaison or elision errors and over-regularizations). Omission and substitution errors are also consistent with an agreement deficit, if, following Ramos (2000a) and Roeper et al. (200I), we understand agreement as being an integral part of the construction of more complex structures within the DP. In fact, omissions and substitutions were observed largely on agreement-bearing elements such as determiners or contracted determiner-prepositions. 
The fact that children with SLI produced over-regularizations was initially surprising, as this behaviour is usually linked to the development of productive linguistic rules in studies of verb acquisition, and is not expected in children with SLI, who have difficulties in this domain (Rice \& Wexler, I 996). However, a closer look at the types of OR found showed that they differed in nature from those usually studied in the literature (i.e. applying an overt suffix onto an irregular verb root or stem), and involved misapplication of morphophonological rules (e.g. liaison). Lexemic overregularization errors were seen only in normally developing children. In sum, children with SLI appear to have difficulties with the automatic application of morphophonological rules, and this problem persists at ages when unimpaired children do not show this behaviour. Because the total numbers of these errors were small, these interpretations need to be supported by further research using specifically targeted data collection methods such as elicitation tasks. However, our error analyses allowed us to pinpoint specific profiles that can emerge in normally developing children and their impaired peers. Such analyses could potentially enable better identification of children with language deficits.

We suggest that future research could focus on French rules of liaison, elision, contraction, and possibly agreement (in its larger sense, as proposed by Ramos, 2000a, and Roeper et al., 2001 ), using elicitation methods, in order to obtain further evidence on questions that have arisen from our corpus analysis, as well as to develop age-appropriate tools for the identification of SLI in children three to five years old. Previous studies have demonstrated the usefulness of elicitation methods for the study of liaison (Chevrot \& Fayol, 200I) in normally developing children aged 3; 0 to 4 ; 5 , and for the study of adjective and determiner agreement in French children as young as 3; 0 with and without SLI (Roulet-Amiot and Jakubowicz, 2006; Roulet, 2007; Royle et al., 20ıо; Royle \& Valois, 2010), as well as complex DP structures in children aged $4 ; 9$ to 5;5 (Ramos, 200oa). These methods could readily be extended to the processes observed here.

In conclusion, we have shown that the syntactic and error analyses of DP production in children can lead to a deeper understanding of SLI and its properties in French. French-speaking children with SLI often produce DPs that are syntactically simpler than those of their age-matched peers, with above-normal omission and commission of obligatory, high-frequency, and early acquired elements such as determiners and prepositions. Insertion errors appear to indicate extra insensitivity to syntactic constraints on DP internal structure. Finally, over-regularization errors, although marginal, suggest that children with SLI occasionally omit the application of obligatory morphophonological rules governing preposition-determiner contraction, liaison, and elision, pointing to a weaker mastery of these processes. These data indicate that in order to account for the observed behaviour, 
linguistic models of SLI have to be more encompassing than those outlined above, most of which focus on only one or two aspects of the morphosyntax interface. None accounts for the morphophonological processing errors, as observed here, although Roeper et al. (200I) propose that a number of different dependencies in the DP can be deficient in SLI. Work by Goad and colleagues (Goad, I998; Gopnik \& Goad, I997) on the morphophonological processes at play in English SLI previously pointed to morphophonological deficits in this domain in some English-speaking patients with SLI (e.g. allomorphy rules for the plural noun suffix). Parisse and Maillart (2008) have recently suggested that phonological difficulties (mainly involving syllable structure integrity) are characteristic of SLI. They stressed the importance of taking phonological abilities into account, at least to describe the deficit. In view of all these findings, it would be appropriate to return to a more general account of SLI, where multiple aspects of grammar, including morphophonological processes, would be expected to be impaired in this population.

\section{REFERENCES}

Bassano, D. (2000). Early development of nouns and verbs in French: Exploring the interface between lexicon and grammar. Fournal of Child Language 27, 52 I-59.

Bates, E. \& Goodman, J. C. (I997). On the inseparability of grammar and the lexicon: Evidence from acquisition, aphasia, and real-time processing. Language and Cognitive Processes I2(5/6), 507-584.

Bedore, L. M. \& Leonard, L. B. (1998). Specific language impairment and grammatical morphology: A discriminant function analysis. Fournal of Speech, Language and Hearing Research 4I(5), I I 85-92.

Bottari, P., Cipriani, P., Chilosi, A. M. \& Pfanner, L. (200 I). The Italian determiner system in normal acquisition, specific language impairment, and childhood aphasia. Brain and Language 77, 283-93.

Chevrot, J.-P. \& Fayol, M. (200I). Acquisition of French liaison and related child errors. In M. Almgren, Andoni Barreña, M.-J. Ezeizabarrena, I. Idiazabal \& B. MacWhinney (eds), Research on child language acquisition: Proceedings of the 8th Conference of the International Association for the Study of Child Language, vol. 2, 76I-75. Somerville, MA: Cascadilla Press.

Clahsen, H. (I989). The grammatical characterization of developmental dysphasia. Linguistics 27, 897-920.

Conti-Ramsden, G. \& Windfuhr, K. (2002). Productivity with word order and morphology: A comparative look at children with SLI and children with normal language abilities. International Fournal of Language and Communication Disorders 37(1), I7-30.

Demuth, K. \& Tremblay, A. (2008). Prosodically-conditioned variability in children's production of French determiners. Fournal of Child Language 35, 99-I27.

Desmarais, C. (2007). Classification du retard de langage à deux ans et analyse des caractéristiques personnelles et sociofamiliales associées et de leur cumul [Classification of later-talkers at age two with an analysis of associated personal and socio-familial characteristics and their combinatory effects]. Unpublished doctoral dissertation, Université Laval, Québec.

Desmarais, C., Sylvestre, A., Meyer, F., Bairati, I. \& Rouleau, N. (2008). Systematic review of the literature on characteristics of late-talking toddlers. International Fournal of Language E Communication Disorders 43(4), 36I-89. 
Dunn, L., Thériault-Whalen, C. \& Dunn, L. M. (1993). Échelle de vocabulaire en images Peabody [French Peabody picture vocabulary test]. Toronto: Psychan.

Elin Thordardottir, Gagné, A., Levy, J., Kehayia, E., Lessard, N., Sutton, A. \& Trudeau, N. (2005). Systematic language sample analysis in French: Normative data for conversation. Paper presented at the Emergence of Language Acquisition, Lyon, France.

Elin Thordardottir \& Namazi, M. (2007). Specific Language Impairment in Frenchspeaking children: Beyond grammatical morphology. Fournal of Speech, Language and Hearing Research 50(3), 698-7 I 5 .

Ellis, E. M. \& Thal, D. J. (2008). Early language delay and risk for language impairment. Perspectives on Language Learning and Education 15, 93-100.

Franck, J., Cronel-Ohayon, S., Chillier, L., Frauenfelder, U. H., Hamann, C., Rizzi, L. \& Zesiger, P. (2004). Normal and pathological development of subject-verb agreement in speech production: A study on French children. Fournal of Neurolinguistics 17(2/3), I $47-8$ o.

Fréchette, R. \& Labelle, M. (2007). Influence of prosody on the production of determiners and adjectives in two-year-old children's sentences. Paper presented at the $32 n d$ Annual Boston University Conference on Language Development, Boston University. Available at: http://www.er.uqam.ca/nobel/r32764/Labelle/Acquisition.html.

Gavin, W. T., Klee, T. \& Membrino, I. (I993). Differentiating Specific Language Impairment from normal language impairment using grammatical analysis. Clinical Linguistics and Phonetics 7, 191-206.

Goad, H. (1998). Plurals in SLI: Prosodic deficit or morphological deficit? Language Acquisition 7(2/4), 247-84.

Gopnik, M. \& Goad, H. (1997). What underlies inflectional error patterns in genetic dysphasia? Fournal of Neurolinguistics 1o, го9-І 37.

Grüter, T. (2005). Comprehension and production of French object clitics by child second language learners and children with Specific Language Impairment. Applied Psycholinguistics 26(3), $3^{6}{ }_{3}-9 \mathrm{I}$.

Hansson, K., Nettelbladt, U. \& Leonard, L. B. (2003). Indefinite articles and definite forms in Swedish children with Specific Language Impairment. First Language 23(3), $348-62$.

Jakubowicz, C. \& Nash, L. (200I). Functional categories and syntactic operations in (ab)normal language acquisition. Brain and Language 77, $32 \mathrm{I}-39$.

Jakubowicz, C., Nash, L., Rigaut, C. \& Gérard, C.-L. (1998). Determiners and clitic pronouns in French-speaking children with SLI. Language Acquisition 7(2/4), I I 3-60.

Le Normand, M.-T., Leonard, L. B. \& McGregor, K. K. (I 993). A cross-linguistic study of article use by children with specific language impairment. European Fournal of Disorders of Communication 28(2), I 53-63.

Leonard, L. B. (1998). Children with specific language impairment. Cambridge, MA: MIT Press.

Leonard, L. B., Salameh, E.-K. \& Hansson, K. (200I). Noun phrase morphology in Swedish-speaking children with Specific Language Impairment. Applied Psycholinguistics 22, 6 I $9-39$.

Miller, J. \& Chapman, R. (1984-2002). Systematic analysis of language transcripts : Software for analyzing English and Spanish language transcripts. University of Wisconsin Madison: Language analysis Laboratory. Available at: www.saltsoftware.com.

OOAQ (2004) Troubles primaires du langage: Dysphasie. Guide et outils cliniques, Trouble primaire du langage/Dysphasie [Primary language impairments: Dysphasie. Guide and clinical tools, primary language impairment/dysphasie]. Unpublished clinical guidelines. Ordre des orthophonistes et audiologistes du Québec.

Pannemann, M. (2007). DP acquisition as structure unraveling. Unpublished doctoral dissertation, Universiteit van Amsterdam.

Paradis, J. \& Crago, M. (2004). Comparing L2 and SLI grammars in child French. In P. Prévost \& J. Paradis (eds), The acquisition of French in different contexts: Focus on functional categories, 89-107. Amsterdam: John Benjamins. 
Paradis, J., Crago, M. \& Genesee, F. (2005/2006). Domain-general versus domain-specific accounts of Specific Language Impairment: Evidence From bilingual children's acquisition of object pronouns. Language Acquisition r3(1), 33-62.

Parisse, C. \& Maillart, C. (2007). Phonology and syntax in French children with SLI: A longitudinal study. Clinical Linguistics and Phonetics 2I( I I/I 2), 945-5 I .

Parisse, C. \& Maillart, C. (2008). The interplay between phonology and syntax in French-speaking children with specific language impairment. International fournal of Language and Communication Disorders 43(4), 448-72.

Paul, R. (I99I). Profiles of toddlers with slow expressive language development. Topics in Language Disorders II, I-I3.

Ramos, E. (2000a). Acquisition of noun phrase structure in children with specific language impairment. Unpublished doctoral dissertation, University of Massachusetts, Amherst. Available at: http://scholarworks.umass.edu/dissertations/AAI9960783/.

Ramos, E. (200ob). Comprehension of definite and indefinite articles in children with SLI. Paper presented at the The 2000 ASHA convention. Available at: www.umass.edu/aae/ ramosartic.pdf.

Restrepo, M. A. (I998). Identifiers of predominantly Spanish-speaking children with language impairment. Fournal of Speech, Language and Hearing Research 4I, I398-4I I.

Restrepo, M. A. \& Gutierrez-Clellen, V. F. (200I). Article use in Spanish-speaking children with SLI. Fournal of Child Language 28, 433-52.

Rice, M. L. \& Wexler, K. (I996). Toward tense as a clinical marker of specific language impairment in English-speaking children. Fournal of Speech, Language and Hearing Research 39, I $236-57$.

Rice, M. L., Wexler, K. \& Cleave, P. (I995). Specific Language Impairment as a period of extended optional infinitive. Fournal of Speech and Hearing Research 38, 850-63.

Roeper, T., Ramos, E., Seymour, H. \& Abdul-Karim, L. (200I). Language disorders as a window on Universal Grammar: An abstract theory of agreement for IP, DP, and V-PP. Brain and Language 77, 378-97.

Roid, G. \& Miller, L. (I996). The Leiter international performance scale-revised. Dale, IL: Wood Stoelting Co.

Rose, Y. \& Royle, P. (I999). Uninflected structure in familial language impairment: Evidence from French. Folia Phoniatrica et Logopedica 5i(1/2), 70-90.

Roulet, L. (2007). L'accord grammatical de genre dans la dysphasie de développement [Grammatical gender agreement in children with SLI]. Psychologie française 52, 55-70.

Roulet-Amiot, L. \& Jakubowicz, C. (2006). Production and perception of gender agreement in French SLI. Advances in Speech-Language Pathology 8(4), 335-46.

Royle, P. (2007). Variable effects of morphology and frequency on inflection patterns of French preschoolers. Mental Lexicon Fournal 2(I), I०3-I 25.

Royle, P. \& Elin Thordardottir (2008). Elicitation of the perfect past in French pre-schoolers with and without SLI. Applied Psycholinguistics 29(3), I-22.

Royle, P., Toupin, J., Bourguignon, N., Trudeau, N. \& Valois, D. (20ro). Déficit de l'accord dans le syntagme nominal chez les jeunes francophones avec un trouble spécifique du langage [Noun phrase agreement deficit in young French speakers with SLI]. $S P E C T R U M$ 2, I-I 8 .

Royle, P. \& Valois, D. (2010). Acquisition of French adjective concord as revealed by elicitation data. Fournal of French Language Studies 2o(30), 3 I 3-38.

Thal, D., Tobias, S. \& Morrison, D. (I99I). Language and gesture in late talkers: A I-year follow-up. Fournal of Speech and Hearing Research 34, 604-6 г 2.

Valois, D. \& Royle, P. (2009). Partitivity, atomization, and N-Drop: A longitudinal study of French child language. Language Acquisition 16(2), 82-105.

Valois, D., Royle, P., Bourdua-Roy, E. \& Sutton, A. (2009). Étude transversale de l'ellipse du nom en français et le rôle des données de l'acquisition pour la théorie linguistique [A cross-sectional study of noun-drop in French: The role of acquisition data for linguistic theory]. Revue canadienne de linguistique / Canadian Fournal of Linguistics 54(2), $339-66$. 
van der Lely, H. K. J. \& Stollwerck, L. (I997). Binding Theory and grammatical specific language impairment in children. Cognition 62, 245-90.

Wauquier-Gravelines, S. \& Braud, V. (2005). Proto-déterminant et acquisition de la liaison obligatoire en français [Proto determiner and acquisition of obligatory liaison in French]. Langages 2(I 58 ), 53-65. 